TP Periodica Polytechnica

Transportation Engineering

43(4), pp. 184-188, 2015

DOI: $10.3311 /$ PPtr.8282

Creative Commons Attribution (i)

RESEARCH ARTICLE

\title{
Safety Level of Airside, Pre-Take-Off Objects and Processes
}

\author{
Dóra Meyer ${ }^{* *}$, Géza Tarnai ${ }^{1}$
}

Received 25 March 2015; accepted 12 June 2015

\begin{abstract}
Preventive, proactive airside, pre-take-off safety in civil air traffic from a new viewpoint with a new toolset on a more exact way with sustaining all necessary principles - to explicate such and similar thoughts is the aim of the paper.
\end{abstract}

\section{Keywords}

new approach of aviation safety, fault tree analysis, fuzzy logic, predictive ALARP control
${ }^{1}$ Budapest University of Technology and Economics

Faculty of Transportation Engineering and Vehicle Engineering

Department of Control for Transportation and Vehicle Systems

H-1111 Budapest, Stoczek street 2, Hungary

\section{Abbreviations}

$\mathrm{AC}$

$\mathrm{AD}$

ALARP

APR

A-SMGCS

ATC

ATCOs

ATM

ATS

EATMN

ESARR

FIS

FPALARP

FTA

$\mathrm{G}$

HMI

HUM

ICAO

JAR-OPS

MET

OPS

PALARP

PAPI

PSA

RWY

SESAR

SMM

SMS

TECH

TWY

$\mathrm{u}$

y
Aircraft

Aerodrome

As Low As Reasonably Practicable Apron

Advanced Surface Movement Guidance

System

Air Traffic Control

Air Traffic Controllers

Air Traffic Management

Air Traffic Services

European Air Traffic Management Network

Eurocontrol Safety Regulatory Requirement

Fuzzy Inference System

Fuzzy Predictive ALARP

Fault Tree Analysis

Integrated air traffic system

Human machine interface

Human parameters

International Civil Aviation Organisation

Joint Airworthiness Requirements

Operations

Meteorological parameters

Operation parameters

Predictive ALARP

Precision Approach Path Indicator

Probabilistic Safety Analysis

Runway

Single European Sky ATM Research

Safety management manual

Safety Management Systems

Technology parameters

Taxiway

Input data

Output data

${ }^{*}$ Corresponding author, e-mail: meyer.dora@mail.bme.hu 


\section{Introduction, system identification}

The level of safety is a specially interesting question in the civil air traffic world. The grounds of examination are such EUROCONTROL predicted air traffic challenges like the traffic increase and increased safety responsibility in this regard. Hazard and risk analysis tasks are fundamentally defining the safety level of air traffic (Koo, Caponecchia, Williamson, 2015; Seneviratne and Molesworth, 2015) and are significantly taken into account as the impact of the running up. the volume of air traffic doesn't stop at pushing the saturation level to its boundaries in the European airspace but radically boosts traffic on airports too (Torok and Heinitz, 2013). Thus the number of potential conflict points and the number of narrow cross-sections is obviously increasing both in space and time.

This paper intends to introduce a risk analysis model, which although comes from a totally new point of view, fits European Air Traffic Strategy. The choice of the topic was driven by its actuality because of the SESAR (Single European Sky ATM Research) initiation.

The currently used aviation safety certification schemes are still task or object oriented (Cui and Li, 2015). Regarding safety certification the aircraft and crew, the staff and infrastructure at the airport and air traffic control; all three units operate mainly but not exclusively independent of each other, attesting excellent safety system (Čokorilo, De Luca and Dell'Acqua, 2014). Safety Management for Air Traffic Management (ATM) is governed by the ESARR 3 (use of Safety Management Systems by ATM Service Providers) and ESARR4. (Risk Assessment and Mitigation in ATM). ICAO Annex 19 describes the necessary safety management provisions and minimum safety management practices. Aerodrome operations, for example, runway maintenance, refuelling, apron management, are governed by the ICAO Annex 14 safety management provisions. Certification of aerodromes is based upon the Aerodrome Operator's Safety Management System. Aircraft Operators have provisions for aerodrome assessment, before commencing flight operations, in their regulations (JAR OPS 1 and 3). Requirements for flight operations to comprise aerodrome specific issues are found in the flight operations manual issued by the Aircraft Operator. Each State manages the sets of rules according to their local needs.

The purpose of the research is to create a structured model for prevention of runway safety examining the formalized system described logical operators actual safety level of the runway determined. The research is looking for a solution process influencing that based on the pre-online definition of risk values. It is ensuring the safety level in ALARP (As low As Reasonably Practicable) range. The research aims to demonstrate and verify the risk level with fuzzy logic. It should be noted, that fuzzy interpretation of the level of risk is not unknown in the world of science, for example considering Harmati (2009) or Takács's $(2009,2010)$ research.
The developed method focuses on the individual flight itself with its own parameters.

\section{The integrated, complex, flight-specific air traffic system model}

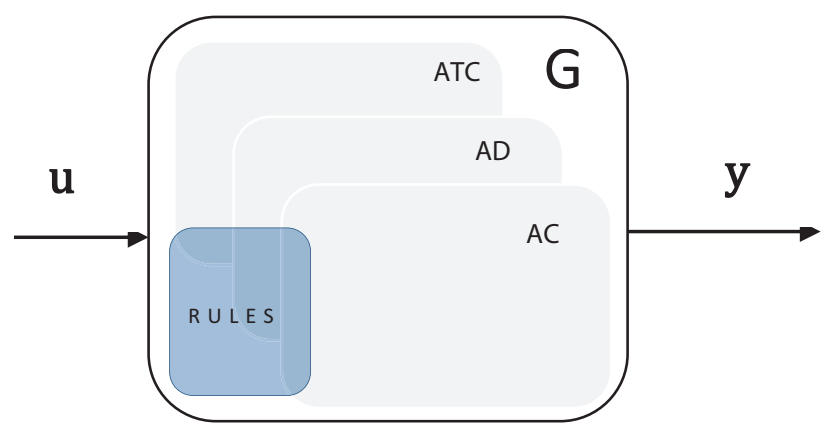

Fig. 1 The integrated air traffic system schematic block diagram model

Based on theory of Zadeh, Polak (1972) abstract objects, function space theory, design attributes mapping of Takeda et. al. (1990), Piros (2012), Čavka, Čokorilo, Vasov, (2015) the integrated aviation, air traffic system model is shown above on Fig. 1. It includes concerning static and dynamic parameters of air traffic control (ATC), aircraft (AC) and airport (AD), like sections of the current air traffic contextual. The novelty of the system approach is based on three attributes: integration, complexity and flight-specificity. The theoretical model includes system infrastructure, meteorological parameters, the system components and agents (human factor) and processes of the loaded, active system as a whole (Cokorilo O. 2013). The system model complexity is given by taking into account the current load parameter groups.

Influencing factors are for example: type and maintenance status of aircraft, type and rate of air cargo, meteorological conditions, traffic complexity at the airport.

The integration involves a flight, flight-specific approach, according to the airside movements as shown on Fig. 2 and 3.

$\alpha_{1}$ APR, apron, apron elements, movements, processes;

$\alpha_{2}$ APR - TWY, apron-taxiway elements, movements, processes;

$\alpha_{3} \quad$ taxiway elements, movements, processes;

$\alpha_{4}$ TWY - RWY, taxiway-runway elements, movements, processes;

$\alpha_{5} \quad$ RWY, runway elements, movements, processes.

From $\alpha_{11}$ to $\alpha_{5 \mathrm{n}}$ the elements, persons, processes were investigated. 
Aerodrome config. \&

\section{G}

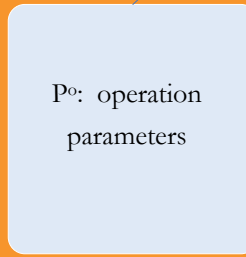

$\mathrm{Ph}$ : human

parameters
Pt: technology parameters
$\mathrm{Pm}$ :

mmeteorological

parameters

Fig. 2 Parameters of integrated air traffic system model

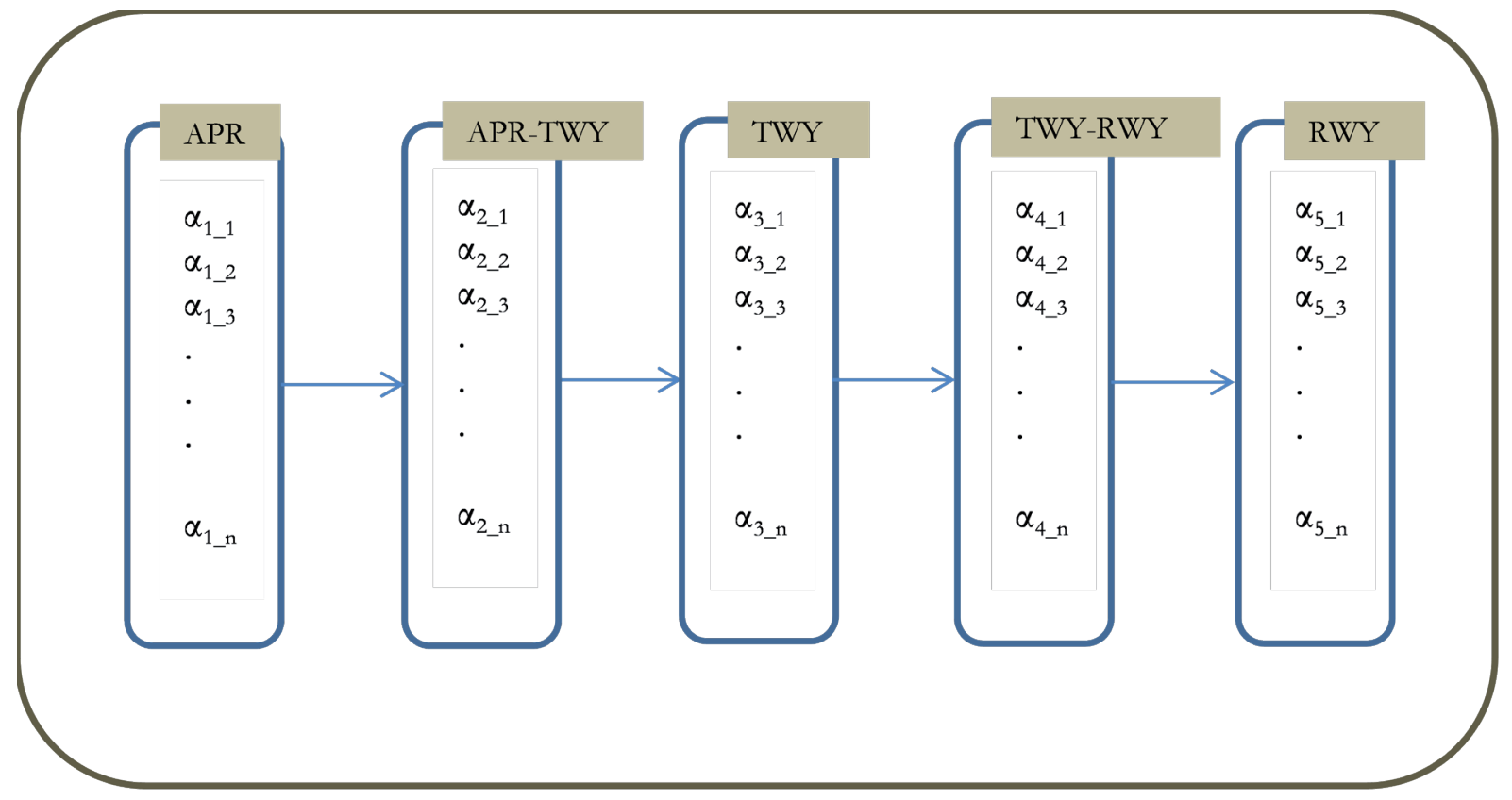

Fig. 3 Parameters of integrated air traffic system model 


\section{Fault tree analysis}

The analysis tool is the PSA - Probabilistic Safety Analysis, with Risc Spectrum PSA Professional - Version 2.10.04 - FTA module using fault tree analysis was performed.

Because of the lack of credible input data the fault tree was built by hypothetical data in accordance with the standards and along professional consultation accepted. The top event is the accident on the runway. The fault tree contains 72 basic events, 2476 minimal cutsets.

Based on the numerical results and the logical analysis stated that according to the runway environment and the calculated level of safety parameters described in the fault tree-structured classification categories corresponding to the high-safety systems fitted to the highest safety integrity classifications.

Based on the analysis of the importance of elementary events and their parameters to the factors influencing the runway accident occurrence probability of the incorrect action absolute human significance. It can also be seen from the importance of elementary events by analyzing and evaluating the minimum cutsets, that human actions are outstanding by relevance of the aircraft captain.

The error significance of the first officer, ramp officer and the support equipment leaders are approaching the failure relevance of the captain. Suboriented, but remaining key elements are the errors where human actions can be traced. Based on the results, the indirect or latent failures have particularly special significance.

The effect of the influence of human error of air traffic control weaker as the failure of tools like A-SMGCS (Advanced Surface Movement Guidance System) to assist the decision.

The significance such airport infrastructure failures like PAPI (Precision Approach Path Indicator) are also dominant. The importance of these approximates the pilot's failure significance.

In general the significant runway accident influence factors are the human decision supporting tools, including the airport's infrastructure and its status.

Factors affecting runway accident occurrence probability the aircraft failure has minor effect as pilots failure or air traffic controllers, or the ATCOs decision supporting systems.

After the FTA, scenario analysis was made with the fault tree. The study confirmed that the characteristics changes of meteorological parameters, human parameters, operation parameters and technology parameters, in those the units concerned are interdependent relations, as shown on Fig. 4. This is the base of the establishment of the fuzzy inference system framework to define the level of safety.

\section{Predictive ALARP with fuzzy logic}

Derived from the fault tree analysis in Matlab was built a group model framework. The first element of the research, the first predictive fuzzy inference system is presented in this paper. The structure of Fuzzy Predictive ALARP Inference System is shown on Fig. 5.

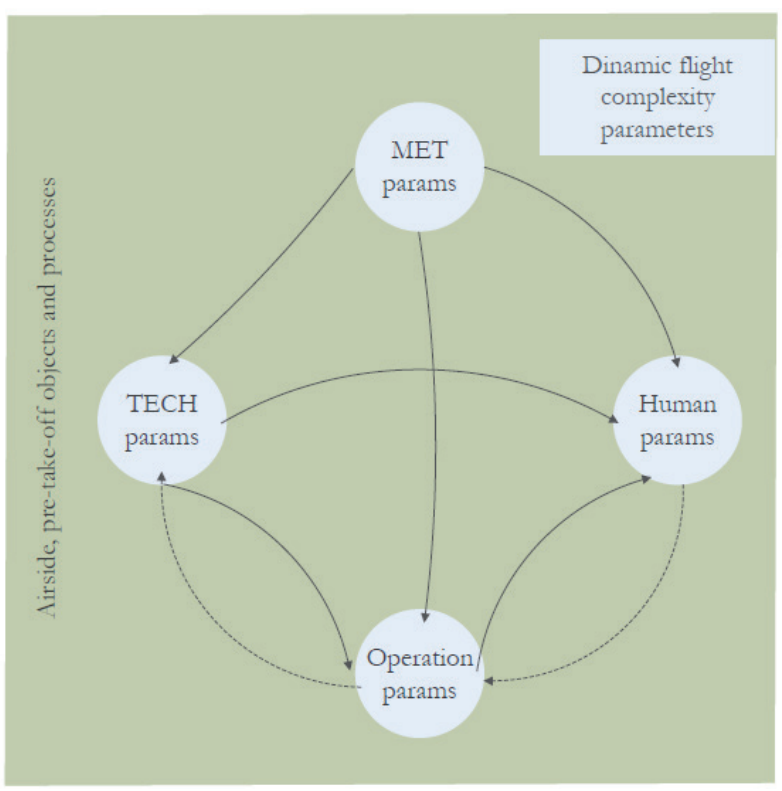

Fig. 4 Dynamic flight complexity parameters

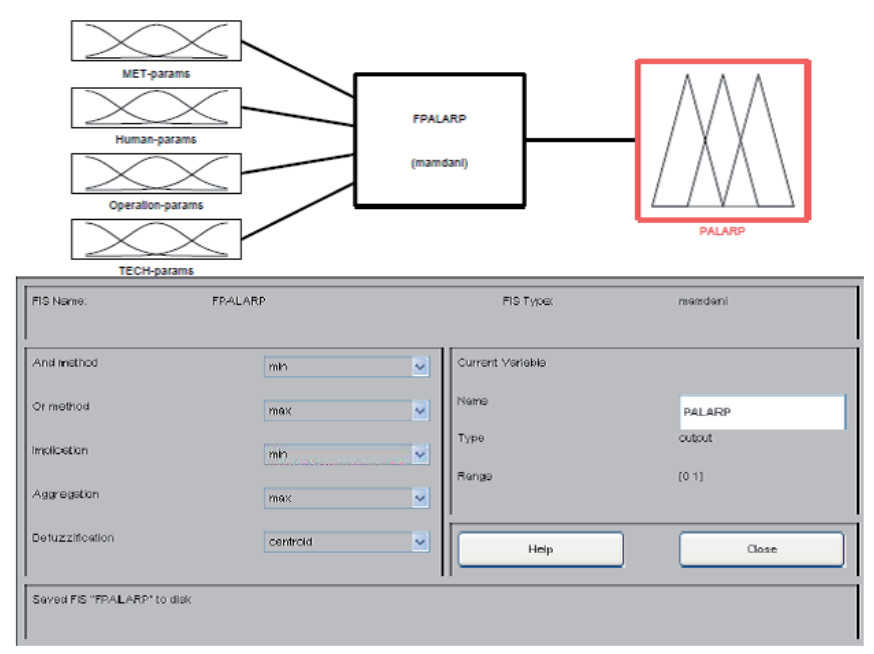

Fig. 5 Fuzzy Predictive ALARP Inference System

Soft computing method (fuzzy logic) was necessary because of the choice of system features, a lot of points because of the lack of an exact description of the system is currently using smart formalization.

Structure, editing and monitoring of FPALARP inference system was built in MATLAB Version 7.2.0.232 (R2006a) using Fuzzy Logic Toolbox.

The research of predictive ALARP control aims to create a pre-online optimum range safety system.

A group model framework has been developed to determine the level of aviation safety. The fuzzy inference system is using an innovative way to:

- the level of safety fuzzy logic inference can be specified;

- such features of the system could also be considered, where the existing research does not provide a solution

- capable of flight safety, actual factors with proven relevance to take into account 
- the comparison of the relevant procedures for effective analysis and highly secure air transport system has determined that the impact of actual dominant factor in many aviation safety relevances in influencing the level of procedures does not appear.

Built into previous scientific human failures achievements by Herczegfi, Izsó (2013), the risk surface of FPALARP Inference System can be seen on Fig. 6.

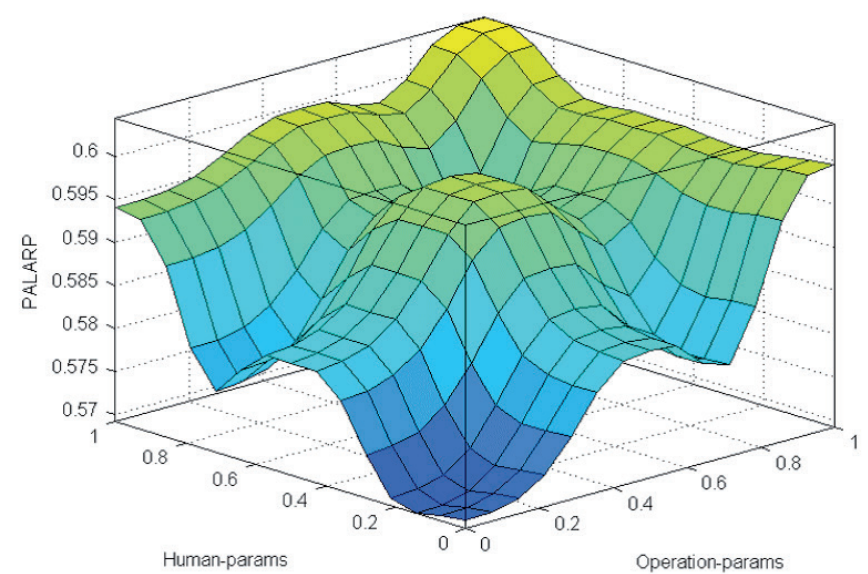

Fig. 6 Risk surface of FPALARP Inference System

\section{Conclusion}

It was created an integrated, complex reliability model fitted to civil aviation runways and their environment that handles the runway and its environment, runway movements as well as the totality of airside, pre-take-off movements and the people and elements involved in such operations, further, meteorological conditions as a functional space unit making a safety critical system which model handles this system in an abstract system of objects - in a novel way as compared to previous results enshrined in special literature.

The actual level of safety is definable with fault tree analysis and fuzzy logic. The research continues with the extension of Predictive Fuzzy ALARP inference system group model framework by clarifying of inputs and rules.

\section{References}

Čavka, I., Čokorilo, O., Vasov, L. (2015) Energy efficiency in aircraft cabin environment: Safety and design. Energy and Buildings.

DOI: 10.1016/j.enbuild.2015.01.015

Cokorilo, O. (2013) Human factor modelling for fast-time simulations in aviation. Aircraft Engineering and Aerospace Technology. 85 (5). pp. 389405. DOI: 10.1108/AEAT-07-2012-0120

Čokorilo, O., De Luca, M., Dell'Acqua, G. (2014) Aircraft safety analysis using clustering algorithms. Journal of Risk Research. 17 (10). pp. 1325 1340. DOI: 10.1080/13669877.2013.879493

Cui, Q., Li, Y. (2015) The change trend and influencing factors of civil aviation safety efficiency: the case of Chinese airline companies. Safety Science. 75. pp. 56-63. DOI: 10.1016/j.ssci.2015.01.015
ESARR3: Use of Safety Management Systems by ATM Service Providers, EUROCONTROL, 2000

ESARR4: Risk Assessment and Mitigation in ATM, EUROCONTROL, 2001 EUROCONTROL Network Operational Concept 2019 [Online] Available from: http://www.eurocontrol.int/sites/default/files/publication/files/jan2015network-operational-concept-2019.pdf [Accessed: 27th May 2015]

Harmati, I. (2009) Jármütest energiaabszorpciós deformációs modelljeinek identifikációja. (The identification of energyabsorption and deformation models of vehicle body). PhD Dissertation, Budapest University of Technology and Economics. (in Hungarian)

Herczegfi, K., Izsó, L. (2010) Ergonómia. (Ergonomy.) Budapest: Typotex. p. 228, (in Hungarian).

ICAO (2013) ICAO Doc 9859, Safety Management Manual (SMM). Third edition, 2013.

ICAO Annex 14, Aerodromes 4 ed. - 2004

ICAO Annex 19, Safety Management 1. ed. - 2013

JAR-OPS 1: Commercial Air Transportation (Aeroplanes), 2007.

Koo, T. T., Caponecchia, C., Williamson, A. (2015) Measuring the effect of aviation safety risk reduction on flight choice in young travellers. Safety Science. 73. pp. 1-7. DOI: 10.1016/j.ssci.2014.10.008

Piros, A. (2012) Application of fuzzy evaluation method based on the construction planning. PhD Thesis, Budapest University of Technology and Economics.

Seneviratne, D., Molesworth, B. R. (2015) Employing humour and celebrities to manipulate passengers' attention to pre-flight safety briefing videos in commercial aviation. Safety Science. 75. pp. 130-135. DOI: 10.1016/j.ssci.2015.01.006

SESAR [Online] Available from: http://ec.europa.eu/transport/air/sesar/ [Accessed: 27th May 2015]

Takács, M. (2010) Multilevel fuzzy approach to the risk and disaster management. Acta Polytechnica Hungarica. 7 (4). pp. 91-102.

Takács, M. (2009) Extended fuzzy methods in risk management. In: 14th WSAES International Conference on Applied Mathematics. pp. 300-304.

Torok, A., Heinitz, F. (2013) Economic impacts on destination air traffic following a flag carrier's market exit: a case study for Budapest. Aviation. 17 (4). pp. 161-169. DOI: 10.3846/16487788.2013.861226

Takeda, H., Veerkamp, P., Tomiyama, T., Yoshikavwa, H. (1990) Modelling Design Process. AI Magazine. 11 (4). pp. 37-48. DOI: 10.1609/aimag.v11i4.855

Zadeh, L. A., Polak, E. (1972) Rendszerelmélet. (System Theory). Budapest: Müszaki Könyvkiadó. (in Hungarian). 